\section{Questión}

Periodismo / Comunicación ISSN 1669-6581

Aplicaciones didácticas de la ciberprensa en la Educación Obligatoria Inmaculada Martín Herrera

Question/Cuestión, Nro.67, Vol.2, diciembre 2020

ISSN: 1669-6581

URL de la Revista: https://perio.unlp.edu.ar/ojs/index.php/question/

IICom - FPyCS - UNLP.

DOI: https//doi.org/10.24215/16696581e410

\title{
Aplicaciones didácticas de la ciberprensa en la Educación Obligatoria
}

Teaching uses of digital press in Compulsory Education school centers

Inmaculada Martín Herrera

Centro Universitario San Isidoro

España

imartin@centrosanisidoro.es

https://orcid.org/0000-0002-8943-4766

\section{Resumen}

El objetivo de este artículo es reflexionar sobre los usos didácticos de la prensa digital en la Educación Obligatoria. Con la revisión bibliográfica se han identificado investigaciones y experiencias docentes, que nos han permitido conocer las aplicaciones educativas de estos medios. Las conclusiones revelan 
que el ámbito escolar apoya la integración curricular de la ciberprensa, tanto por sus beneficios en el proceso de enseñanza y aprendizaje como por sus usos docentes, entre los que figuran la lectura de noticias, ser un complemento al libro de texto y la realización de debates. Igual de importante son las competencias que adquieren los alumnos, pues los habilita para ser prosumidores responsables de información en la Red, mientras gestionan su propio aprendizaje en un entorno colaborativo y conectado con la actualidad.

\section{Palabras clave}

medios de comunicación; prensa; Internet; Educación Obligatoria; alfabetización mediática.

\section{Abstract}

The aim of this article is reflecting on the didactic uses of digital press in school centers of Compulsory Education. With the bibliographic review carried out, teaching researches and experiences have been identified, which have allowed us to know the teaching purposes of these means. Conclusions reveal that teachers support the integration of digital press in schools, both due to the benefits in the teaching and learning process as well as for their teaching uses, among them, the reading of news, the fact that it is a complement to the coursebook and the organization of debates. As important as these are the students' competences, since they empower students to become consumers of information in the Net, at the same time that they manage their own learning in a collaborative environment which is connected with the news. 


\section{Keywords}

mass media; press; Internet; Compulsory Education; media literacy.

\section{Introducción}

Internet es una gigantesca biblioteca digital y un valioso banco de recursos para profesores y alumnos. Según Polo (2014, p. 29), la Red es «un enorme reflejo del mundo, una ventana que podemos usar en nuestra clase para que niños y adolescentes entiendan cómo funciona el flujo de información y aprendan a reaccionar de forma inteligente ante el mismo". Se trata de un canal en permanente actualización, donde la información se retroalimenta y se difunde de manera vertiginosa de un emisor a millones de receptores. Además, ha propiciado un incremento y un acceso prácticamente inmediato a los medios de comunicación electrónicos en una «sociedad hipercomunicada» (Caldeiro \& Aguaded, 2015, p. 37).

La cantidad de datos presentes en la Red y el impacto que ello supone pone de relieve la importancia y la responsabilidad de informadores y de docentes, los cuales pueden y deben orientar a los usuarios en la búsqueda y en la creación de la información. Hablamos de la adquisición de unas capacidades «para entender los medios y sus contenidos, usos y mediaciones a través de proyectos educomunicativos de interés ciudadano» (Vélez, 2017, p.15). En definitiva, unas competencias mediáticas que deben abordarse desde la escuela mediante una educación, igualmente mediática, que «requiere de una aplicación práctica» (Aguaded, Marín \& Díaz, 2015, p. 292).

Salinas (2005) ya vaticinó el proceso de cambios y desafíos en los que se encuentra inmerso el sistema educativo. Para el autor, los cibermedios exigen nuevas destrezas, pero también contribuyen a su logro y dominio; y en ello 
reside uno de los papeles cruciales que los canales informativos online pueden desarrollar en la educación.

Al abordar los usos docentes de la prensa digital en los centros escolares, hay que tener en cuenta que los alumnos y las alumnas de hoy en día son nativos digitales. Este término fue acuñado por Prensky (2001) para designar a los hablantes nativos del lenguaje digital, de las computadoras, los videojuegos e Internet. A partir de ese momento, cobra especial importancia identificar y establecer límites generacionales, con objeto de estudiar a estos grupos humanos para obtener información acerca de cómo se comunican y cómo reaccionan ante los fenómenos sociales y tecnológicos. Así pues, se comienza a hablar de los millennials o Generación $\mathrm{Y}$, que son los primeros en crecer y educarse al amparo del "desarrollo sociotécnico de la red de redes, internet, la web y sus extensiones móviles e inteligentes» (Fumero, 2016, p. 11); y los centennials o Generación Z, nacidos a partir de 1995 y los primeros puramente nativos digitales. Estos postmillennials dan paso a la generación más joven, que incluye a aquellos que nacen en la actualidad: la Generación $T$, también conocida como Generación Táctil, Generación Tecnológica o Generación Alfa (Cataldi \& Dominighini, 2019).

En estas generaciones, el proceso comunicativo se vuelve más activo, hasta convertirse en el hito principal en torno al cual se construye la vida y sus relaciones. Se caracterizan por su «voracidad comunicativa (más visual que textual) y de consumo digital (contenidos, aplicaciones, etc.)» (Quintana, 2016, p.127). Estos niños y jóvenes aprenden y aprovechan desde muy temprano el potencial de relación y de comunicación que tiene Internet. Y estas habilidades implican unas oportunidades y unos riesgos que deben ser asumidos por parte de educadores y comunicadores. 
En relación al consumo que los menores hacen de los medios online, la Red es un canal que les permite acceder a datos actualizados sobre sus temas de interés. En este sentido, la investigación de Feijoo (2015) pone de manifiesto que, aunque el empleo de las redes sociales $(52,8 \%)$ es notablemente superior al de los cibermedios $(4,1 \%)$, la prensa online no es completamente ajena a los niños y niñas. Considerando el perfil y las demandas informacionales de estos menores, y respecto a los retos que plantea el actual entorno tecnológico y sociocultural, Prensky (2014) expone que necesitamos transformar el currículo para orientar la educación hacia el futuro y que pueda ser válida para estudiantes nacidos en la era de Internet y los medios digitales. La principal razón, según este autor, es que las publicaciones online, usadas correctamente en las aulas, pueden ayudar a volver el aprendizaje de nuestros alumnos y alumnas conectado con la realidad, atractivo y útil.

Estimamos que la enseñanza y el uso de los medios electrónicos en las etapas de la Educación Primaria y Secundaria de los niños y los jóvenes es fundamental para su posterior desarrollo como adulto; de manera que puedan integrarse personal y profesionalmente, y abordar temas de todo tipo: técnicos, económicos, sociales, etc. Por tanto, hay que dejar a un lado algunos de los hábitos educativos convencionales y experimentar con medios alternativos, como es el caso de la prensa digital; participar en redes de aprendizaje colaborativo; incorporar el lenguaje hipertextual a las prácticas escolares; fomentar la participación, más igualitaria y democrática, que permiten los recursos interactivos; monitorizar los resultados para detectar las necesidades de los alumnos; y apreciar el interés y el buen manejo innato que los estudiantes hacen de sus smartphones, tabletas, ordenadores, aplicaciones, webs, redes sociales, etc. 
En base a esta propuesta, el objetivo de este trabajo es indagar en los usos didácticos de la prensa digital en la Educación Obligatoria. Para ello, se ha empleado una metodología fundamentada en la revisión teórica de autores y de aquellas experiencias docentes donde la ciberprensa se emplea como herramienta de alfabetización mediática; y muy especialmente, como un recurso docente que puede utilizarse de manera exitosa en las diferentes asignaturas del currículum escolar.

\section{La integración educativa de la prensa digital}

Los medios de comunicación y las tecnologías han modificado la manera de aprender, así como la forma de construir y de divulgar el conocimiento. Debido a estos cambios, la irrupción de los cibermedios en la vida y en las relaciones de los ciudadanos provoca unas demandas específicas a la institución educativa. Esta perspectiva del problema plantea la necesidad de algún tipo de respuesta pedagógica por parte del centro escolar que dote a los niños y jóvenes de las capacidades que les faciliten una relación crítica con la propuesta mediática a la que están expuestos cuando navegan por Internet. También supone redefinir la relación de la escuela con los medios de comunicación. En concreto, nos referimos a la relación de integración y uso de la prensa digital en el aula con fines educativos. Pues el hecho de que los medios de comunicación reflejen la realidad, al mismo tiempo que la interpretan y valoran, justifica los beneficios y la necesidad de utilizarlos en el aula.

Alonso, Ospina y Sánchez (2014) apuestan por esta integración para que la prensa electrónica sea utilizada con un propósito pedagógico en la escuela y en la universidad, como un recurso interdisciplinar que permite, mediante su transversalidad, integrar las distintas áreas del conocimiento en los procesos 
curriculares, con el objetivo de formar un lector crítico en los niveles de la educación básica, media y superior. De manera que la consulta de estas publicaciones permite al estudiante estar informado sobre las realidades nacionales e internacionales, y construir su propio conocimiento y criterio cultural del contexto que lo rodea, "convirtiéndose en un sujeto analítico, reflexivo, crítico y democrático acerca de las problemáticas sociales» que se despliegan en su entorno cotidiano y social (2014, p.107).

Little (2014) también apoya la integración escolar de la ciberprensa, pues opina que los periódicos, en su versión impresa o digital, juegan un papel importante en la educación de los estudiantes porque son la mejor manera de aprender sobre el mundo. Para esta autora, es el momento de explotar todas las posibilidades de los soportes electrónicos, por su relación con Internet, teniendo en cuenta que los centros trabajan con niños y jóvenes que viven y estudian conectados a la Red. De modo que, por su condición de nativos digitales y su relación natural con las tecnologías, su presencia en Internet es mayor en proporción que la de otros grupos de edad (Feijoo, 2015); y estas circunstancias convierten a la escuela es un espacio idóneo para aplicar procesos de educomunicación con la prensa online.

García y Contreras (2018, p. 32) proponen el concepto de escuela prosumidora, donde estos cibermedios se emplean como un recurso didáctico para «enseñar, mostrar, informar, motivar, investigar y evaluar...»y también como un medio de creación y expresión. Se trata, en cualquier caso, de una incorporación transversal, pues estos canales informativos "pueden ser utilizados en todas las materias y disciplinas curriculares, así como en todos los niveles educativos" (p. 32). 
En definitiva, autores y organismos (Parlamento Europeo, 2008; Aguaded, Marín \& Díaz, 2015; Semali, 2017) consideran necesaria la integración de la asignatura educación mediática en el currículum escolar de Primaria y de Secundaria, así como «la explotación didáctica de los cibermedios» (Vázquez \& Calvo, 2015, p. 267). A su vez, De la Fuente (2014, p. 453) plantea que estas acciones educativas se desarrollen a través de una metodología «que no se limite a la alfabetización funcional, sino que también sea capaz de fomentar procesos de enseñanza/aprendizaje dentro del contexto de los medios de comunicación».

\section{Beneficios del aprendizaje con los cibermedios}

La revisión teórica de experiencias docentes y de autores que han investigado sobre el tema nos ha permitido conocer los beneficios de la integración de la prensa electrónica en el aula. Amar (2010) destaca la posibilidad de hablarles a los alumnos en su propio registro idiomático, lo que facilita el entendimiento de conceptos útiles en su desarrollo personal y profesional. Para Romano (2017), el uso de estos medios puede estimular el desarrollo de habilidades lingüísticas, metalingüísticas y contextuales de los alumnos como lectores y escritores contemporáneos.

González (2010, p. 55) habla de «recompensas y de efectos inmediatos». Para este autor, el uso de las noticias de las publicaciones digitales, desde su propia experiencia con alumnos de Educación Secundaria Obligatoria, conlleva lo siguiente: aumenta el interés del alumnado por seguir las clases; focaliza la atención hacia la actualidad; disminuye la dispersión del alumno en el aula; favorece la disciplina; mejora la credibilidad del profesorado; descubre los medios de comunicación a los alumnos; favorece el intercambio de opiniones y 
los debates; fomenta clases más conectadas con el tiempo actual; aporta aire fresco a la dinámica de las clases; favorece muchas actividades posteriores; ayuda a contextualizar temas con una visión más amplia; incita a la enseñanza del lenguaje multimedia; ayuda a expresarse al alumno de forma oral y escrita con el apoyo de las TIC; y obliga al profesorado a ser innovador.

A su vez, estas ventajas radican en las propias peculiaridades de la ciberprensa: la continua actualización y la variedad de contenidos, la fácil accesibilidad, el poder trabajar con noticias reales, y el lenguaje hipertextual, que posibilita ampliar la información y configurar un periódico a la carta en función de los gustos y las necesidades de los estudiantes.

Los cibermedios contribuyen al desarrollo cognitivo de los alumnos. Así pues, según Ballesta y Bernal (2013), introducir la actualidad en el aula y crear contenidos periodísticos propios en la Red propicia un aprendizaje permanente a lo largo de la vida con objeto de ejercer una ciudadanía activa. Por su parte, un trabajo de Buil, Hernández y Sesé (2013) defiende el uso académico de la prensa, tanto en papel como en formato electrónico, para la mejora de los procesos de aprendizaje. Los resultados argumentan que favorece el desarrollo de las competencias genéricas y específicas de la asignatura, pues según el alumnado, al trabajar con estos medios periodísticos comprenden mejor los conceptos. Además, las actividades realizadas con el apoyo de la ciberprensa incrementan la capacidad de análisis, síntesis y crítica. En concreto, los estudiantes aprendieron a identificar las partes elementales de cada noticia, y establecer la interrelación entre las mismas, así como entre éstas y los contenidos de la asignatura. Igualmente, estas prácticas mejoran la comunicación escrita de los alumnos, esto es, su capacidad para trasmitir conocimientos y expresar argumentos e ideas de forma clara y rigurosa. $Y$ 
también aumentan las opciones de participación del estudiante en su proceso de aprendizaje.

Mora y Aguaded (2019) consideran que los materiales periodísticos son «recursos motivacionales para que el discente pueda aprender contenidos no solo conceptuales sino también actitudinales y procedimentales» ( $p .71)$. Y añaden que, empleados como documentos formativos, facilitan el aprendizaje de los medios de comunicación en distintas áreas como matemáticas, ciencias sociales, lenguaje, idiomas..., mediante actividades fáciles y motivantes.

A pesar de estas posturas favorables, la escuela permanece fuera del debate generado por el poder didáctico de los medios online. Como consecuencia, aún no existe una aceptación de estas materias en los currículos oficiales, y la integración de la prensa digital en los centros escolares es hoy en día insuficiente. En este sentido, la investigación de Alonso et al. (2014, p.102) determina el escaso uso que la escuela hace de la prensa escrita y online; a pesar de ser «una herramienta pedagógica y didáctica que propicia un acercamiento a los diferentes tipos de textos que los estudiantes, próximos a terminar su educación media, deben identificar, comprender, interpretar, analizar y producir».

Entre los hándicaps que perjudican la integración escolar de los diarios digitales figuran la escasa equipación informática de las escuelas y el insuficiente nivel de conocimiento tecnológico de los profesores y los alumnos (Cabero, 2000; Valdés, Angulo, Urías, García \& Mortis, 2011; Mur, 2016; Pérez \& Rodríguez, 2016). Para Feijoo (2015), lo que falla desde el sector educativo es el poco compromiso de los centros docentes con los proyectos de prensaescuela y una falta de colaboración a la hora de integrar la prensa digital como un recurso habitual en las aulas. Igualmente, el profesorado también hace 
referencia a otros factores como la falta de tiempo, de oportunidades y de motivación, así como el escaso apoyo de la Administración Pública (Martín, 2017).

En cualquier caso, de cara a un aprendizaje efectivo con la ciberprensa, debemos pensar en estrategias específicas (comunicativas, tecnológicas y sociales) con las que se puede trabajar en el aula, y que preparan a los estudiantes para ser ciudadanos de una sociedad informacional y digitalizada. Por lógica, los resultados dependerán del método pedagógico que adopte el maestro. Por ello, para la integración y el uso de la prensa digital como un instrumento didáctico, el sistema educativo debe asumir cambios en sus infraestructuras y, también, en su mentalidad docente.

\section{Aplicaciones docentes de la prensa digital}

Los profesores y los alumnos de hoy en día son ciudadanos 'prosumidores', cuyas competencias deberían estar encaminadas, por un lado, a hacer un consumo crítico de los medios de comunicación; y por otro, a producir contenidos responsables y creativos, de manera constructiva y autónoma (García, Ramírez \& Rodríguez, 2014). Y estas particularidades y destrezas deben ser tenidas en cuenta a la hora de pensar en la prensa digital como una herramienta para la educación en los centros escolares, pues la actualidad es uno de los recursos más atractivos en la enseñanza.

Con el uso de las publicaciones digitales se rompe el modelo de enseñanza puramente transmisivo (Álvarez, 2007), basado en los conocimientos y en el profesor. Dice Cebrián (2009, p.10) que en el sistema de comunicación educativa que propone la ciberprensa sobresale el papel que adquieren ambos públicos, profesores y alumnos, siendo estos últimos autores de «su 
aprendizaje mediante el dominio de los navegadores y buscadores de información, la interactividad y los enlaces que interrelacionan datos e informaciones para conseguir conocimientos y habilidades". De manera que el estudiante se convierte en protagonista al pasar de ser un receptor pasivo de su maestro-emisor a «un usuario activo e interactivo del autoaprendizaje con las correspondientes orientaciones y tutelaje» (Cebrián, 2009, p.10).

La literatura consultada (Pinilla, 2008; Gadea, Vilches \& Gil, 2009; Said, 2010; Amar, 2010; Ballesta \& Bernal, 2013; Feijoo, 2015;) nos sirve de inspiración para proponer las siguientes aplicaciones didácticas de la prensa online. La ciberprensa puede servir como apoyo a los materiales curriculares, buscando ejemplos o aportando contenidos complementarios a los que aparecen en los libros de texto, permitiendo la realización de actividades interactivas, fomentando la lectura y el aprendizaje de vocabulario, y proporcionando noticias que sirvan como excusa para el debate, la opinión y la producción oral y escrita, lo que contribuye a crear una clase democrática y más participativa.

A estas actividades sumamos otras tareas que son posibles con el apoyo de la prensa digital, y que cuentan con la importante ventaja de que se pueden adaptar a la edad y al nivel académico de los estudiantes: contextualizar la información, familiarizarse con los conceptos de interactividad e hipertextualidad, elaborar documentos multimedia y trabajos colaborativos a través de las herramientas que conforman la 'nube' (Google Drive, Dropbox, WeTransfer, Flickr, etc.), contrastar los hechos con otros cibermedios y con las propias experiencias de los alumnos, interaccionar con estos diarios publicando comentarios propios, analizar la calidad e idoneidad de los recursos audiovisuales publicados en estos soportes, «hacer una hemeroteca de aula; elaborar reseñas de artículos y de respuestas a los mismos; confeccionar 
dossiers informativos y trabajos monográficos sobre cuestiones de actualidad; redactar artículos de divulgación» (Gadea et al., 2009, p.159) y crear un periódico digital escolar.

La investigación de Suárez (2015) determina que los periódicos digitales deportivos pueden ser utilizados como herramienta para enseñar retórica al alumnado de Educación Secundaria Obligatoria. Este trabajo derivó en la elaboración de cinco unidades didácticas, con actividades que se pueden trabajar de manera individual y colectiva, y que son susceptibles de incluir en el currículo en la asignatura Lengua y Literatura.

Sobre un género concreto: la infografía periodística digital, Ruiz (2020) considera que es un medio útil en educación, pues motiva al alumnado a explorar una información que se presenta a través de distintos formatos: textos, ilustraciones y gráficas. Por ello, «tiene potencial para documentación, análisis y comprensión informativa técnica, científica, académica, etc.» (p. 430). Además, «brinda desarrollos cognitivos necesarios en entornos hiperconectados: autoaprendizaje, análisis, planeación y organización» ( $p$. 430), y posibilita conductas éticas.

Con objeto de recopilar estas propuestas, y haciendo un desglose por asignaturas, exponemos una serie de usos de la ciberprensa en materias de la Educación Obligatoria (Cuadro 1): 


\begin{tabular}{ll}
\hline Lengua y Literatura & Matemáticas, Física y Química \\
\hline - comentarios de texto & - análisis de gráficas \\
- estudiar los textos periodísticos & - leer noticias con cifras y porcentajes \\
- ejercicios de gramática y ortografía & - resolver problemas estadísticos \\
- comprensión lectora y expresión & - analizar diagramas publicados en \\
oral & noticias \\
- aprender vocabulario & - leer noticias sobre experimentos e \\
- redactar textos de opinión & inventos \\
& - conocer aplicaciones prácticas de la \\
& ciencia \\
\hline Plástica & Música \\
\hline - leer noticias sobre arte & - leer críticas de conciertos \\
- buscar fotografías sobre obras de & - leer noticias culturales \\
arte & \\
\hline Historia & Ciudadanía \\
\hline - hacer comentarios históricos & - comentar noticias sobre valores \\
- organizar debates & éticos \\
- complemento al libro de texto & - leer noticias sobre la libertad \\
- introducir una clase & personal \\
- apoyo a la clase con imágenes & - explicar problemas sociales \\
\hline Inglés & - hacer murales sobre la paz, la \\
\hline
\end{tabular}




\begin{tabular}{ll}
\hline - leer noticias en inglés & - emplear la ciberprensa como \\
- aumentar el vocabulario & herramienta \\
- hacer traducciones & - leer noticias sobre avances \\
& tecnológicos \\
& - hacer un periódico digital escolar \\
\hline Ciencias sociales y naturales & Educación Física \\
\hline - leer noticias sobre política & - leer críticas deportivas \\
- leer noticias sobre medio ambiente & - análisis de anuncios de marcas \\
- contextualizar temas de geografía & deportivas \\
política & - concienciar en contra de la violencia \\
\cline { 2 - 2 } - investigaciones en equipo & Latín \\
\cline { 2 - 2 } - buscar y exponer un tema & - leer noticias sobre la Antigua Roma \\
\hline
\end{tabular}

Cuadro 1: Usos de la prensa digital en asignaturas de la Educación Obligatoria. Fuente: elaboración propia

Y en base a la información expuesta, la siguiente Figura 1 resume las ventajas del uso de la prensa digital en el aula: 


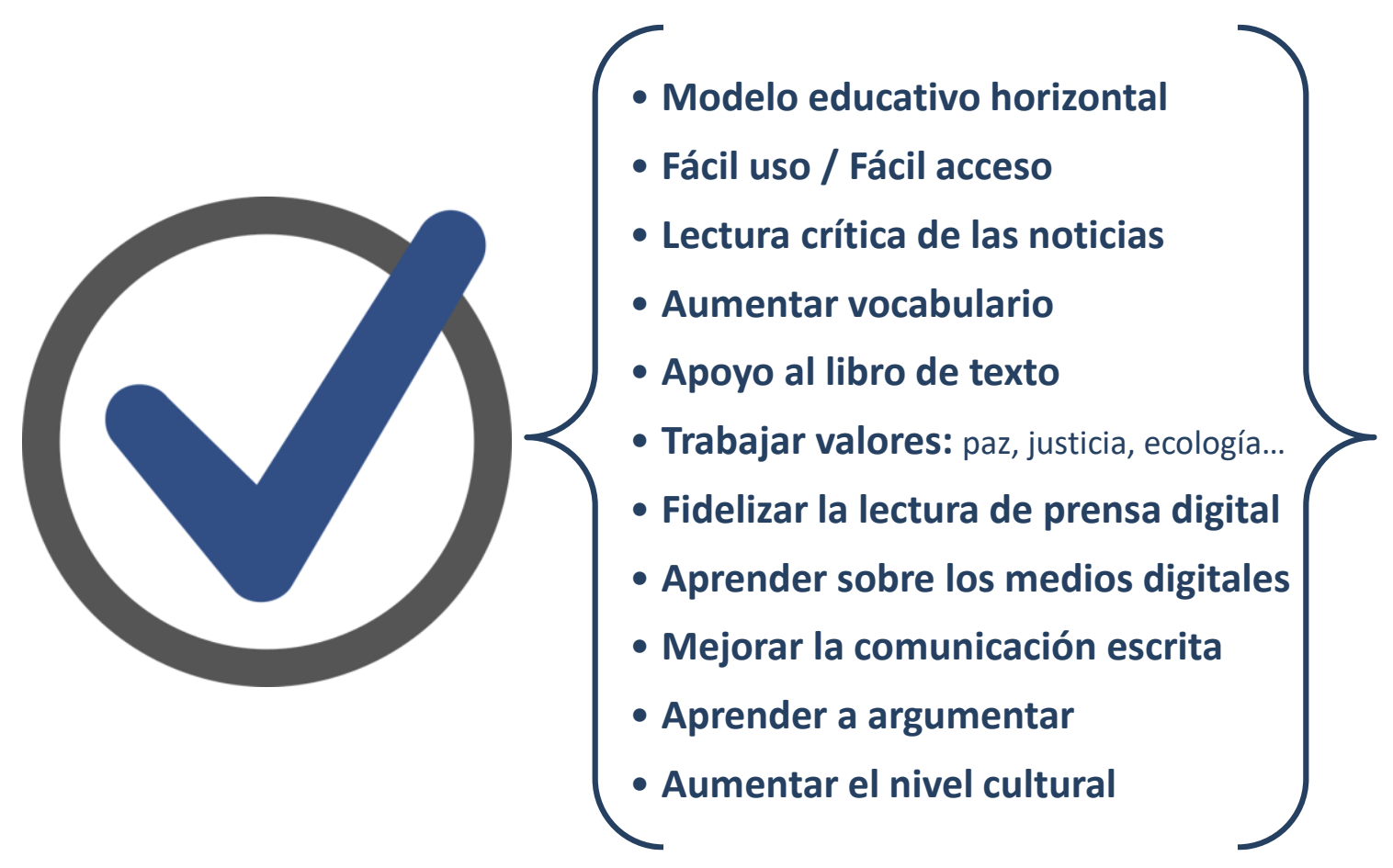

Figura 1: Ventajas del uso de la prensa digital en la educación. Fuente: elaboración propia

Igualmente, existen desventajas y riesgos. Así pues, las actividades o proyectos educativos con la prensa digital requieren de equipos informáticos y del acceso y manejo de las herramientas adecuadas: ordenadores, conexión a Internet y navegadores. Si se trata de poner en marcha una publicación escolar en la Red, también es necesario disponer y tener conocimiento de editores de imágenes, procesadores de texto, y programas o gestores de contenidos para el diseño de la web y el mantenimiento de la página: WordPress, Blogger, Edublogs, etc. Otro requisito es la formación específica del profesorado, porque con esta alfabetización: mediática, tecnológica y social, aprenderá a aplicar las 
TIC y obtendrá orientación acerca de cómo emplear la ciberprensa como una herramienta didáctica en sus asignaturas.

Spanhel (2011) resume estas apreciaciones al afirmar que una educación sostenible con los medios online implica dos dificultades. Por un lado, la mayor parte del profesorado no está adecuadamente entrenado para utilizar los soportes periodísticos de forma eficaz y temen enfrentarse a ello. En este sentido, un trabajo de Tárraga, Sanz, Pastor y Fernández (2017) revela que en el caso de los futuros maestros de Infantil y Primaria estos se perciben a sí mismos como más competentes en el uso de las TIC que en la toma de decisiones pedagógicas relacionadas con su empleo en el aula; y valoran positivamente la formación específica recibida a este respecto. En segundo lugar, la educación con medios requiere modelos de enseñanza abiertos, así como instalaciones específicas con acceso fácil, a cualquier hora del día y en cualquier momento.

Además, la dedicación del profesor debe ser intensiva. Pues al mismo tiempo que educa a sus alumnos en medios digitales, debe controlarlos para que usen el ordenador convenientemente, no accedan a contenidos inapropiados, empleen la información obtenida de estos soportes de una manera ética y legal, respeten la propiedad intelectual y se dediquen a las tareas encomendadas. Ya que es fácil distraerse con los muchos y atractivos recursos de la web, como es el caso de los gráficos, los anuncios dinámicos y los enlaces a otros sitios de Internet.

A continuación, representamos estos aspectos negativos del uso docente de la prensa electrónica que acabamos de describir (Figura 2). 


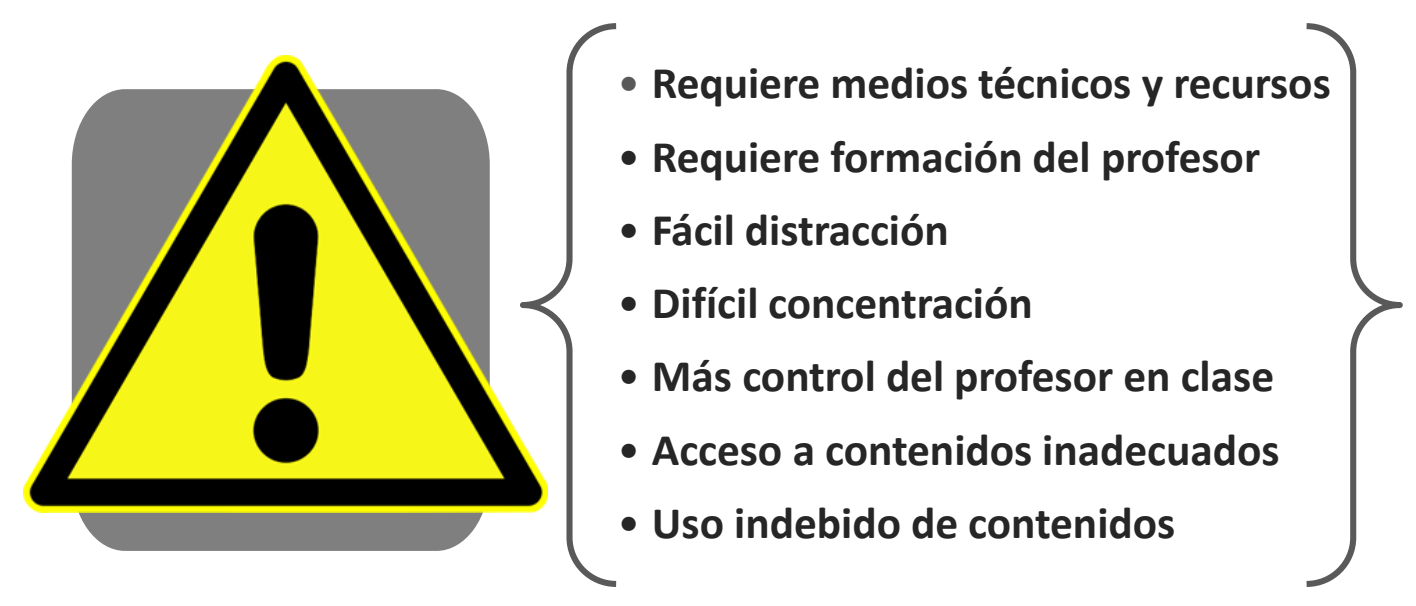

Figura 2. Aspectos negativos del uso de la prensa digital en la educación.

Fuente: elaboración propia

\section{Competencias del alumno al ser formado con la ciberprensa}

Al ser formados con medios tecnológicos, los alumnos adquieren una serie de competencias. Según Wilson (2012, p.8), «las competencias en alfabetización mediática e informacional capacitan a los individuos para acceder, organizar y evaluar la información, y para producir medios y textos informativos». Por este motivo, para Cabero y Guerra (2011, p.91), es destacable «la relación que hay entre la alfabetización en medios de una persona y sus habilidades, actitudes, etc. con respecto a formas de consumo, pensamiento crítico y reflexivo, ciudadanía participativa, etc.».

Sobre lo que pueden aprender los alumnos con el uso de la prensa digital en el aula, Jaillier (2010) expone las siguientes estrategias, cada una de las cuales es una posibilidad para abordar la relación propuesta entre competencias y ciberprensa en procesos de aprendizaje significativo: 
(a) Estrategias de búsqueda. Implican ser críticos frente a la búsqueda de información en la Red. Además de conocer los diferentes géneros periodísticos y distinguir los informativos de la opinión.

(b) Estrategias de almacenaje y organización de la información.

(c) Estrategias analíticas para comprender los contenidos digitales.

(d) Estrategias de toma de decisiones colaborativa entre los miembros de la clase.

(e) Estrategias sociales. Aprovechando el potencial de las herramientas y los servicios ofrecidos por los periódicos digitales para motivar actividades que desarrollen las competencias de asociación o de trabajo en equipo.

Por su parte, la revisión bibliográfica (Amar, 2005 y 2010; Cabero \& Guerra, 2011; Ferrés \& Piscitelli, 2012, Perrenoud, 2012; Wilson, 2012; Oliveras, Márquez \& Sanmartí, 2013; López \& Aguaded, 2015) sobre dimensiones e indicadores de la alfabetización mediática, nos ha permitido elaborar un catálogo de las competencias que adquieren los alumnos gracias a la educación en medios de comunicación electrónicos. Siguiendo la clasificación temática propuesta por Ferrés (2007), estas habilidades son las que se exponen a continuación:

\section{(a) Lenguaje}

- Conocimiento de los códigos (visuales, sonoros y textuales). Capacidad para utilizarlos y para analizar mensajes escritos y audiovisuales desde la perspectiva del sentido y el significado, de las estructuras narrativas y de los géneros, distinguiendo entre ficción y no ficción.

Prepararse para un manejo autónomo y reflexivo de la información, de sus lenguajes y herramientas, promoviendo el pensamiento crítico (describir, 
comparar, relacionar, clasificar, etc.) con la finalidad de posibilitar la adquisición o mejora de habilidades intelectuales para seleccionar, analizar y comprender el contenido de los medios.

(b) Tecnología

- Conocimiento y capacidad de utilización de las herramientas que hacen posible la comunicación en la Red para entender cómo se elaboran los mensajes.

- Comprensión del papel que desempeñan las TIC en la sociedad.

- Usar eficientemente las TIC para realizar aprendizajes.

(c) Procesos de interacción

- Capacidad de seleccionar y autoevaluar la propia dieta mediática.

- Capacidad de valorar críticamente los elementos cognitivos, racionales, emocionales y contextuales que intervienen en la recepción de los mensajes.

- Desarrollar la capacidad de comunicarnos competentemente con los cibermedios.

- Promover el consumo activo y equilibrado, y la interacción entre las personas. Acceder, analizar y evaluar mensajes de los cibermedios de forma crítica, emitiendo juicios de valor propios.

(d) Procesos de producción y difusión

- Conocimiento de las funciones y tareas de los agentes de producción, las fases de los procesos de producción y difusión, y los códigos de regulación.

- Capacidad para elaborar, compartir y diseminar mensajes mediáticos en Internet. 
- Reflexionar y aprender conceptos como la no-transparencia de los medios, los géneros periodísticos, la objetividad, la agenda-setting y los filtros de la información en Internet (Ballesta \& Céspedes, 2016).

Ser un activador del conocimiento.

Participación real del estudiante en su proceso de aprendizaje mediante la creación de materiales que sean el producto de su acción investigativa.

(e) Ideología y valores

- Fomentar la libertad de expresión y la investigación.

- Educarse en la contemporaneidad: aprender sobre política, sociedad, cultura, etc.

Evidenciar cómo influyen en las personas los mensajes de los medios online.

(f) Estética: Capacidad de analizar y de valorar los mensajes audiovisuales desde el punto de vista de la innovación formal y temática y la educación del sentido estético.

Ante la importancia de adquirir estas competencias, el papel de la escuela debe ser el de preparar a los estudiantes para la recepción crítica de información digital. Y también para la producción creativa y la participación como emisores en la Red. Pues hoy en día, con la Web 3.0 o semántica, fundamentada en los contenidos publicados y compartidos, el ciudadano es un individuo influenciado $y$, al mismo tiempo, influyente. Precisamente porque no podemos obviar las particularidades y exigencias de la sociedad digital en la que vivimos, la educación para los mass media supone la integración curricular de la prensa electrónica. 


\section{Conclusiones y discusión}

Al indagar sobre los usos académicos de la prensa digital en la Educación Obligatoria, la revisión bibliográfica nos ha permitido deducir que, en general, el ámbito educativo apoya la integración escolar de las publicaciones online porque estos medios son la mejor manera de aprender sobre el mundo (Little, 2014) en clases más conectadas con la actualidad (González, 2010); optimizan el proceso de aprendizaje (Buil et al., 2013); permiten «aplicaciones en el campo de la comunicación educativa y una mayor innovación pedagógica» (Cebrián, 2009, p. 10); y son un recurso interdisciplinar con carácter transversal (Alonso et al., 2014; Romano, 2017; García \& Contreras, 2018) para trabajar en el aula y desarrollar programas de educación mediática.

Estos alegatos a favor de la ciberprensa como recurso educativo se sustentan sobre los beneficios que aporta al proceso de enseñanza y aprendizaje. Así pues, se trata de una fuente de datos abierta, cuyos contenidos se actualizan permanentemente. $Y$ es un canal que facilita la comunicación interpersonal, la interactividad entre los alumnos y el trabajo colaborativo, permitiendo el desarrollo de nuevos métodos que motivan a los estudiantes (Marquès, 2013). Para Liu (2019, p. 10), quien ha investigado la integración de los cibermedios en la educación primaria en China, la prensa online favorece un «aprendizaje centrado en el alumno». Además, su estudio determinó que la aplicación de estos medios electrónicos facilita al profesorado el logro de sus objetivos de enseñanza.

También existen riesgos e inconvenientes, pues el empleo docente de la prensa digital requiere, por un lado, de medios técnicos y recursos, con los que no cuentan todas las escuelas; y por otro, de una formación específica del 
profesorado y de modelos de enseñanza abiertos (Spanhel, 2011). Además, la dedicación del profesor debe ser intensiva para garantizar la concentración en clase, y evitar el acceso a contenidos inadecuados o el uso indebido de los mismos.

Las aplicaciones escolares de la prensa electrónica son muchas y variadas; y permiten la necesaria conexión entre la teoría sobre educación mediática y la práctica real (Liu, 2019). Los cibermedios pueden servir parar introducir una clase y como apoyo a las asignaturas curriculares, a través de noticias que fomentan el debate en aulas más participativas. Otras tareas son aprender vocabulario, familiarizarse con los conceptos de lenguaje multimedia, interactividad e hipertextualidad, estudiar las peculiaridades de los textos periodísticos, leer noticias con cifras, gráficas y porcentajes, leer noticias en inglés, realizar comentarios de textos, interactuar con estos medios publicando comentarios propios, aprender a contrastar los hechos y elaborar un periódico digital escolar.

Respecto a las competencias que adquieren los alumnos al trabajar en clase con la prensa digital, destaca el manejo autónomo de la información, de sus lenguajes y sus herramientas, con la finalidad de lograr o mejorar habilidades intelectuales para seleccionar críticamente, evaluar y comprender los contenidos publicados en los cibermedios. Otras competencias son la capacidad para elaborar, difundir y compartir mensajes mediáticos en Internet; así como promover el consumo activo, pero equilibrado, y la interacción entre las personas. Igualmente, el uso educativo de los medios online fomenta el trabajo en equipo, que incluye la participación en debates y la toma de decisiones colaborativas. Al mismo tiempo que el alumno aprende a usar 
eficientemente los medios digitales para realizar aprendizajes y convertirse, de esta manera, en un activador de su propio conocimiento.

Estas conclusiones avalan la conveniencia de trabajar en el aula con los medios online, máxime si tenemos en cuenta, por su perfil de nativos digitales, la habilidad innata de los estudiantes a la hora de manejar dispositivos electrónicos y de navegar en la Red. No obstante, ante las necesidades detectadas, se precisan acciones formativas dirigidas al profesorado, de modo que aprenda a explicar y emplear en sus asignaturas conceptos y recursos ciberperiodísticos; así como mejoras en las infraestructuras escolares. Pues ambas carencias, formativas y tecnológicas, explican, en parte, la escasa presencia de estas plataformas informativas en las rutinas escolares.

Finalmente, de cara a su integración curricular, se sugieren futuras investigaciones acerca de las relaciones que existen entre la prensa digital y el centro escolar. En este sentido, algunas propuestas son seguir estudiando qué aprenden y cómo aprenden los alumnos mediante la elaboración y el mantenimiento de publicaciones escolares digitales; o bien, realizar un estudio cualitativo, mediante la técnica de focus group, donde profesores y alumnos discutan sus necesidades y propuestas respecto al uso didáctico de la ciberprensa.

\section{Referencias bibliográficas}

Aguaded, J.I., Marín, I. \& Díaz, E.M. (2015). La alfabetización mediática entre estudiantes de primaria y secundaria en Andalucía (España). RIED: Revista Iberoamericana de Educación a Distancia, 18(2), 275-298. 
Alonso, R., Ospina, P. \& Sánchez, P.A. (2014). Aulas prensa. Hacia una lectura crítica de artículos de opinión en la educación media. Actualidades Pedagógicas, 63, 99-116.

Álvarez, P. (2007). La prensa como recurso en educación ambiental: análisis de una experiencia. Comunicar, 29, 165-172.

Amar, V. (2005). Educar en medios: educar para las pantallas. Tavira, 21, 215227.

Amar, V. (2010). La educación en medios digitales de comunicación. Pixel-Bit, $36,115-124$.

Ballesta, J. \& Bernal, M. (2013). Comprender la actualidad en el aula y desarrollar el pensamiento crítico a través de la prensa digital. En Actas del II Congreso Internacional Educación Mediática y Competencia Digital. 941-952. Recuperado de https://www.uoc.edu/portal/es/symposia/congreso ludoliteracy2013/concl usiones actas/ACTAS DEFINITIVAS CONGRESO EDUMED 2013.pdf

Ballesta, J. \& Céspedes, R. (2016). Educación para los medios en un entorno digital. Investigación-acción en Compensación Educativa. Revista Lasallista de Investigación, 13(1), 156-165.

Buil, I., Hernández, B. \& Sesé, F.J. (2013). El papel de la prensa en la mejora del proceso de aprendizaje: Una aplicación en el EEES. Revista de Docencia Universitaria, 11(3), 445-459.

Cabero, J. (Dir.). (2000). Uso de los medios audiovisuales, informáticos y las nuevas tecnologías en los centros andaluces. Sevilla, España: Editorial Kronos. 
Cabero, J. \& Guerra, S. (2011). La alfabetización y formación en medios de comunicación en la formación inicial del profesorado. Educación XXI, 14(1), 89-115.doi: dx.doi.org/10.5944/educxx1.14.1.264

Caldeiro, M.C. \& Aguaded, I. (2015). Alfabetización comunicativa y competencia mediática en la sociedad hipercomunicada. Revista digital de investigación en docencia universitaria, 9(1), 37-56.

Cataldi, Z., \& Dominighini, C. (2019). Desafíos en la Educación Universitaria para el 2030. Más allá de la generación Z: Pensando en la generación Alfa. Revista de Informática Educativa y Medios Audiovisuales, 17(25), $1-6$.

Cebrián, M. (2009). Comunicación interactiva en los cibermedios. Comunicar, 33, 15-24. doi: 10.3916/c33-2009-02-001.

De la Fuente, J. (2014). Alfabetización mediática: del prosumidor al profesional. Historia y comunicación social, 19(2), 451-464.

Feijoo, B. (2015). La prensa digital y las redes sociales en la actividad 2.0 de los menores gallegos. Icono 14, 13(1), 30-51. doi: 10.7195/ri14.v13i1.739

Ferrés, J. (2007). La competencia en comunicación audiovisual: dimensiones e indicadores. Comunicar, 29, 100-107.

Ferrés, J. \& Piscitelli, A. (2012). La competencia mediática: propuesta articulada de dimensiones e indicadores. Comunicar, 38, 75-82.

Fumero, A. (2016). JóveneZ. Revista de Estudios de Juventud, 114, 11-27.

Gadea, I., Vilches, A. \& Gil, D. (2009). Posibles usos de la prensa en la educación científica y tecnológica. Didáctica de las Ciencias Experimentales y Sociales, 23, 153-169. 
García, R., Ramírez, A. \& Rodríguez, M.M. (2014). Educación en alfabetización mediática para una nueva ciudadanía prosumidora. Comunicar, 43,1523. doi: 10.3916/C43-2014-01.

García, R. \& Contreras, P. (2018). La escuela prosumidora: del recurso didáctico al contenido curricular. En García, R., Pérez, A. y Torres, A. (ed). (2018). Educar para los nuevos Medios. (pp. 28-42). Quito, Ecuador: Editorial Universitaria Abya-Yala.

González, E. (2010). La prensa digital. Un recurso para educar en cibercomunicación con la actualidad mundial, en Said, E. (ed.). Tics, comunicación y periodismo digital. (pp. 51-71). Colombia: Ediciones Uninorte.

Jaillier, E. (2010). Prensa Escuela y los cibermedios. Posibilidades de utilización para la formación en competencias, en Said, E. (ed.). Tics, comunicación y periodismo digital. (pp. 17-30). Colombia: Ediciones Uninorte.

Little, C. (2014). Newspapers excel in educating our students. Recuperado de https://eu.democratandchronicle.com/story/opinion/guestcolumn/2014/03/06/web-essay-newspapers-excel-educatingstudents/6142045/

Liu, M. (2019). Bringing Media to Classroom: Integrating Digital Media into Student-Centered Learning Environments - A Case Study in one Elementary School in China. (Master's Thesis). China: Tampere University

López, L. \& Aguaded, M.C. (2015). La docencia sobre alfabetización mediática en las facultades de Educación y Comunicación. Comunicar, 44, 187195. 
Marquès, P. (2013). Impacto de las TIC en la educación: funciones y limitaciones. 3C TIC: cuadernos de desarrollo aplicados a las TIC, 2(1). Recuperado de http://www.3ciencias.com/wpcontent/uploads/2013/01/impacto-de-las-tic.pdf

Martín, I. (2017). Actitudes docentes hacia la integración curricular de la prensa digital en los centros escolares de Educación Obligatoria. Enseñanza \& Teaching, 35(1), 39-63.

Mora, B. y Aguaded, M.C. (2019). Murales prensa-escuela: la prensa como recurso didáctico. Aularia, 2, 57-72

Mur, L. (2016). La nueva brecha digital docente. El futuro de las nuevas tecnologías en Primaria desde la formación del profesorado. Revista Electrónica Interuniversitaria de Formación del Profesorado, 19(2), 301313.

Oliveras, B., Márquez, C. \& Sanmartín, N. (2013). The use of newspaper articles as a tool to develop critical thinking in science classes. International Journal of Science Education, 36(6), 885-905.

Parlamento Europeo (2008). EI PE sugiere introducir una asignatura de «educación mediática» en las escuelas europeas. Bruxelles: European Parlament. Recuperado de https://www.europarl.europa.eu/sides/getDoc.do?language=es\&type=IMPRESS\&reference $=20081216$ IPR44614

Pérez, A. \& Rodríguez, M.J. (2016). Evaluación de las competencias digitales autopercibidas del profesorado de educación primaria en Castilla y León. Revista de Investigación Educativa, 34(2), 399-415. 
Perrenoud, P. (2012). Cuando la escuela pretende preparar para la vida. ¿Desarrollar competencias o enseñar otros saberes? Barcelona, España: Editorial Graó.

Pinilla, R. (2008). Las posibilidades del periodismo digital como fuente de material didáctico para el aula de ELE, en Pastor Cesteros, S. y Roca Marín, S. (coord.). La evaluación en el aprendizaje y la enseñanza del español como lengua extranjera/segunda lengua. (pp. 489-496). Alicante: Universidad de Alicante.

Polo, J.D. (2014). Qué significa internet en la educación. Aprender para educar con tecnología, 8, 28-29.

Prensky, M. (2001). Digital natives, digital immigrants. On the Horizon, 9(5), 16.

Prensky, M. (2014). Teaching and Training in the Third Millennium. Conferencia en el congreso SIMO Educación 2014.

Quintana, Y. (2016). Generación Z: vuelve la preocupación por la transparencia online. Revista de Estudios de Juventud, 114, 127-142.

Romano, M.B. (2017). Educación y medios en la escuela secundaria argentina: la mirada de los estudiantes. Actualidades Investigativas en Educación, 17(3), 1-33.

Ruiz, M. (2020). La infografía digital periodística y su aporte a la prensa escolar. Kepes, 17(21), 395-435

Said, E. (ed.). (2010). Tic's, comunicación y periodismo digital. Colombia: Uninorte.

Salinas, J. (2005). Nuevos escenarios de aprendizaje. Actas del IV Congreso de Formación para el Trabajo (pp. 421-431). España: IFES, Fundación Forcem y Universidad de Vigo. 
Semali, L.M. (2017). Literacy in multimedia America: Integrating media education across the curriculum. London: Routledge.

Spanhel, D. (2011). Un enfoque para integrar la educación en medios, en la instrucción y en el día a día de la escuela secundaria. Enseñanza \& Teaching, 29(1), 181-190.

Suárez, S. (2015). Los titulares en los cibermedios deportivos. Principales figuras retóricas y su aplicación didáctica. (Tesis Doctoral). Cáceres, España: Universidad de Extremadura.

Tárraga, R., Sanz, P., Pastor, G. \& Fernández, M.I. (2017). Análisis de la autoeficacia percibida en el uso de las TIC de futuros maestros y maestras de Educación Infantil y Educación Primaria. Revista Electrónica Interuniversitaria de Formación del Profesorado, 20(3), 107116. DOI: http://dx.doi.org/10.6018/reifop.20.3.263901

Valdés Á.A., Angulo, J., Urias, M.L., García, R.I \& Mortis, S.V. (2011). Necesidades de capacitación de docentes de educación básica en el uso de las TIC. Pixel-Bit. Revista de Medios y Educación, 39, 211-223.

Vázquez, E. \& Calvo, E. (2015). Adolescentes y cibermedios. Una didáctica basada en aplicaciones periodísticas para smartphones. Estudios pedagógicos, 41(2), 255-270. doi:10.4067/S0718-07052015000200015

Vélez, I. (2017). La formación en alfabetización mediática y competencia digital. Revista Fuentes, 19(2), 15-19.

Wilson, C. (2012). Alfabetización mediática e informacional: proyecciones didácticas. Comunicar, 39, 15-24. doi: 10.3916/C39-2012-02-01. 